\title{
Liquid-Liquid Extraction of Transition Metal Cations by Glyoximes and Their Macrocyclic Glyoxime Ether Derivatives
}

\author{
Nazan Karapinar, ${ }^{1}$ Emin Karapinar, ${ }^{2}$ and Emine Ozcan ${ }^{3}$ \\ ${ }^{1}$ Chemistry Engineering Department, Engineering Faculty, Pamukkale University, 20070 Denizli, Turkey \\ ${ }^{2}$ Department of Chemistry, Faculty of Arts and Sciences, Pamukkale University, 20070 Denizli, Turkey \\ ${ }^{3}$ Department of Chemistry, Faculty of Arts and Sciences, Selçuk University, 42031 Konya, Turkey
}

Correspondence should be addressed to Nazan Karapinar; nkarapinar@pau.edu.tr

Received 29 March 2013; Accepted 14 May 2013

Academic Editor: Saima Q. Memon

Copyright (C) 2013 Nazan Karapinar et al. This is an open access article distributed under the Creative Commons Attribution License, which permits unrestricted use, distribution, and reproduction in any medium, provided the original work is properly cited.

Liquid-liquid extraction of various alkalis $\left(\mathrm{Li}^{+}, \mathrm{Na}^{+}, \mathrm{K}^{+}\right.$, and $\left.\mathrm{Cs}^{+}\right)$, transition metals $\left(\mathrm{Co}^{2+}, \mathrm{Ni}^{2+}, \mathrm{Cu}^{2+}, \mathrm{Zn}^{2+}, \mathrm{Cd}^{2+}\right.$, and $\left.\mathrm{Hg}^{2+}\right)$, and $\mathrm{Pb}^{2+}$ cations with phenylglyoxime (L1), p-tolylglyoxime (L2), $N^{\prime}-\left(4^{\prime}\right.$-Benzo[15-crown-5])phenylaminoglyoxime (L3), and $N^{\prime}-\left(4^{\prime}-\right.$ Benzo[15-crown-5])-p-tolylaminoglyoxime (L4) from the aqueous phase into the organic phase was carried out. For comparison, the corresponding two glyoximes and their macrocyclic glyoxime ether derivatives were also examined. Crown ether groups having ligands $(\mathbf{L 3}, \mathbf{L 4})$ carry especially $\mathrm{Na}^{+}$cation from aqueous phase to organic phase. The extraction equilibrium constants $\left(K_{\mathrm{ex}}\right)$ for complexes of ligands with $\mathrm{Cu}^{2+}$ and $\mathrm{Hg}^{2+}$ metal picrates between dichloromethane and water have been determined at $25^{\circ} \mathrm{C}$. The values of the extraction constants $\left(\log K_{\text {ex }}\right)$ were determined to be $12.27,13.37,12.94$, and 12.39 for $\mathrm{Cu}^{2+}$ and $10.29,10.62,11.53$, and 11.97 for $\mathrm{Hg}^{2+}$ with L1-L4, respectively.

\section{Introduction}

Of the multitude of macrocycles known, oxygen-containing compounds have been used extensively in extraction, because of the excellent compatibility between the crown-ring sizes and the ionic radii of metals. Solvent extraction with crown ethers is a convenient method for metal analysis because of their high selectivity and affinity towards specific metals. The benzene ring introduces much higher lipophilicity of a crown ether than the cyclohexyl ring does according to their distribution ratios $[1,2]$. Besides, other pendent substituents on the crown ring also enhance the lipophilicity [3].

Crown ethers have been found to be powerful extracting agents for alkali metal salts [4]. They are also accepted to be model compounds to mimic antibiotics in cation transport through lipid membranes [5].

The presence of both mildly acidic hydroxyl groups and slightly basic nitrogen atoms makes $(E, E)$-dioximes amphoteric ligands which form corrin-type square planar, square pyramidal, and octahedral complexes with nickel(II),
cobalt(II), copper(II), palladium(II), and cobalt(III) as central metal atoms [6-17].

We report here a comparison of the solvent extractions of metal ions $\left(\mathrm{Li}^{+}, \mathrm{Na}^{+}, \mathrm{K}^{+}, \mathrm{Cs}^{+}, \mathrm{Co}^{2+}, \mathrm{Ni}^{2+}, \mathrm{Cu}^{2+}, \mathrm{Zn}^{2+}\right.$, $\mathrm{Cd}^{2+}, \mathrm{Hg}^{2+}$, and $\mathrm{Pb}^{2+}$ ) by the glyoxime and their macrocyclic glyoxime ether derivatives.

\section{Experimental}

2.1. Chemicals and Equipment. Figure 1 shows the formula of L1-L4. Phenylglyoxime (L1) [12, 13], p-tolylglyoxime (L2) [14], $N^{\prime}$-(4'-Benzo[15-crown-5])phenylaminoglyoxime (L3) [9], and $N^{\prime}-\left(4^{\prime}\right.$-Benzo[15-crown-5])-p-tolylaminoglyoxime (L4) [10] were prepared according to published methods. All reagents were purchased from Merck (Germany) and were used without further purification. All aqueous solutions were prepared with deionized water that had been passed through a Millipore Milli-Q Plus water purification system. UV/VIS spectra were recorded on a Shimadzu 160A spectrometer. 
<smiles>[R]C(=NO)C(=[NH2+])Cl</smiles><smiles>[R]C(=N)C(=N)Nc1ccc2c(c1)OCCOCCOCCOCC2</smiles>

L1-L2 R: $\mathrm{C}_{6} \mathrm{H}_{5^{-}}, \mathrm{CH}_{3^{-}} \mathrm{C}_{6} \mathrm{H}_{4^{-}}$

FIgURE 1: Formula of L1-L4.

2.2. Solvent Extraction. Picrate extraction experiments were performed following Pedersen's procedure [18]. $10 \mathrm{~mL}$ of a $2 \cdot 10^{-5} \mathrm{M}$ aqueous picrate solution and $10 \mathrm{~mL} 1 \cdot 10^{-3} \mathrm{M}$ solution of ligand in $\mathrm{CH}_{2} \mathrm{Cl}_{2}$ were vigorously agitated in a stoppered glass tube with a mechanical shaker for $2 \mathrm{~min}$, then magnetically stirred in a thermostated water bath at $25^{\circ} \mathrm{C}$ for $1 \mathrm{~h}$, and finally left standing for an additional $30 \mathrm{~min}$. The concentration of the picrate ion remaining in the aqueous phase was then determined spectrophotometrically, as previously described [19]. Blank experiments showed that no picrate extraction occurred in the absence of ligand. The alkali picrates were prepared as described elsewhere [19] by stepwise addition of a $2 \cdot 10^{-2} \mathrm{M}$ aqueous picric acid solution to a $0.14 \mathrm{M}$ aqueous solution of alkali metal hydroxide until neutralization, which was checked by $\mathrm{pH}$ control with a glass electrode. They were then rapidly washed with ethanol and ether before being dried in vacuo for $24 \mathrm{~h}$. Transition metal picrates were prepared by successive addition of a $1 \cdot 10^{-2} \mathrm{M}$ metal nitrate solution to $2 \cdot 10^{-5} \mathrm{M}$ aqueous picric acid solution and shaken at $25^{\circ} \mathrm{C}$ for $1 \mathrm{~h}$. These metal picrates $\left(\mathrm{Li}^{+}, \mathrm{Na}^{+}, \mathrm{K}^{+}, \mathrm{Cs}^{+}, \mathrm{Co}^{2+}, \mathrm{Ni}^{2+}, \mathrm{Cu}^{2+}, \mathrm{Zn}^{2+}, \mathrm{Cd}^{2+}, \mathrm{Hg}^{2+}\right.$, and $\mathrm{Pb}^{2+}$ ) were measured by $\mathrm{UV}$ using does maximum wavelength $(357,349,349,349,349,361,349,357,349,349$, and $346 \mathrm{~nm}$ ). The extractability of the metal cations is expressed by means of the following equation (1):

$$
\text { Extractability }(\%)=\left[\frac{A_{0}-A}{A_{0}}\right] \times 100 \text {, }
$$

where $A_{0}$ and $A$ are the absorbencies in the absence and presence of ligands, respectively.

2.3. $\log$-Log Plot Analyses. To characterize the extraction ability, the dependence of the distribution coefficient $D$ of the cation between the two phases on the ligand concentration was examined. If the general extraction equilibrium is given by (2).

$$
\mathrm{M}_{(\mathrm{aq})}^{n+}+n \mathrm{Pic}_{(\mathrm{aq})}^{-}+x[\mathrm{~L}]_{(\mathrm{org})} \longrightarrow\left[\mathrm{M}(\mathrm{Pic})_{n}(\mathrm{~L})_{x}\right]_{(\mathrm{org})},
$$

the overall extraction equilibrium constant is

$$
K_{\mathrm{ex}}=\frac{\left[\mathrm{M}(\mathrm{Pic})_{n}(\mathrm{~L})_{x}\right]}{\left[\mathrm{M}^{n+}\right]\left[\mathrm{Pic}^{-}\right]^{n}[\mathrm{~L}]^{x}},
$$

TABLE 1: Metal picrates and medium $\mathrm{pH}$ used in extraction.

\begin{tabular}{ccccccccc}
\hline Metals & $\cong \mathrm{pH}$ & $\mathrm{Ni}^{+2}$ & $\mathrm{Co}^{+2}$ & $\mathrm{Cu}^{+2}$ & $\mathrm{Zn}^{+2}$ & $\mathrm{Cd}^{+2}$ & $\mathrm{~Pb}^{+2}$ & $\mathrm{Hg}^{+2}$ \\
\hline \multirow{4}{*}{$\mathrm{pH}$} & 2,00 & 2,17 & 2,01 & 2,03 & 2,07 & 2,01 & 2,11 & 2,11 \\
& 3,00 & 3,00 & 2,99 & 3,01 & 2,99 & 2,94 & 3,01 & 3,06 \\
& 4,00 & 4,00 & 3,64 & 4,02 & 3,92 & 3,81 & 4,18 & 3,95 \\
& 5,00 & 4,77 & 4,72 & 4,80 & 4,95 & 4,74 & 4,80 & 4,96 \\
\hline
\end{tabular}

TABLE 2: Extraction of metal cations with L1 (\%).

\begin{tabular}{lcccc}
\hline \multirow{2}{*}{ Metals } & \multicolumn{4}{c}{ \% Extraction } \\
& $\mathrm{pH} \cong 2,00$ & $\mathrm{pH} \cong 3,00$ & $\mathrm{pH} \cong 4,00$ & $\mathrm{pH} \cong 5,00$ \\
\hline $\mathrm{Ni}^{+2}$ & $54,54 \pm 0,81$ & $12,74 \pm 0,45$ & $4,50 \pm 0,36$ & $5,67 \pm 0,40$ \\
$\mathrm{Co}^{+2}$ & $71,33 \pm 0,32$ & $24,29 \pm 0,24$ & $1,00 \pm 0,09$ & $10,12 \pm 0,18$ \\
$\mathrm{Cu}^{+2}$ & $67,46 \pm 0,29$ & $42,89 \pm 0,69$ & $63,61 \pm 0,86$ & $70,44 \pm 1,01$ \\
$\mathrm{Zn}^{+2}$ & $65,61 \pm 0,46$ & $11,37 \pm 0,34$ & $1,47 \pm 0,17$ & $1,16 \pm 0,15$ \\
$\mathrm{Cd}^{+2}$ & $71,00 \pm 0,12$ & $22,91 \pm 0,38$ & $7,32 \pm 0,28$ & $3,66 \pm 0,12$ \\
$\mathrm{~Pb}^{+2}$ & $63,42 \pm 1,06$ & $24,06 \pm 0,11$ & $6,62 \pm 0,16$ & $5,74 \pm 0,17$ \\
$\mathrm{Hg}^{+2}$ & $46,38 \pm 0,17$ & $21,20 \pm 0,20$ & $20,93 \pm 0,19$ & $13,33 \pm 0,18$ \\
\hline
\end{tabular}

${ }^{\mathrm{a}} \mathrm{H}_{2} \mathrm{O} / \mathrm{CH}_{2} \mathrm{Cl}_{2}=10 / 10(\mathrm{v} / \mathrm{v})$; [ picric acid] $=2 \times 10^{-5} \mathrm{M}$, [ligand] $=1 \times 10^{-3} \mathrm{M}$, and [metal nitrate] $=1 \times 10^{-2} \mathrm{M}, 298 \mathrm{~K}, 1 \mathrm{~h}$ contact time.

Averages and standard deviations calculated for data are obtained from five independent extraction experiments.

and the distribution ratio $D$ is defined by

$$
D=\frac{\left[\mathrm{M}(\mathrm{Pic})_{n}(\mathrm{~L})_{x}\right]}{\left[\left(\mathrm{M}^{n+}\right)\right]} .
$$

By introducing $D$ into (4) and taking logarithm of both sides, (5) is obtained:

$$
\log D=\log \left(K_{\mathrm{ex}}\left[\mathrm{Pic}^{-}\right]^{n}\right)+x \log [\mathrm{L}] .
$$

Under these assumptions, a plot of $\log D$ versus $\log$ [L] should be linear and its slope should be equal to the number of ligand molecules per metal cation in the extracted species.

\section{Result and Discussion}

Although numerous investigations have been recently reported regarding the extraction of alkali metals and transition metals from aqueous phase into an organic phase by crown ether [20-23], as yet, reports on solvent extraction with the complexes of oxime compounds were scarce [24-30]. Therefore, we have investigated the solvent extraction of metal cations through crown ether-based oxime compounds. In this work, we have investigated the effectiveness of four glyoxime derivatives in transferring the alkaline metal cations $\left(\mathrm{Li}^{+}, \mathrm{Na}^{+}, \mathrm{K}^{+}\right.$, and $\left.\mathrm{Cs}^{+}\right)$, transition metals $\left(\mathrm{Co}^{2+}, \mathrm{Ni}^{2+}, \mathrm{Cu}^{2+}\right.$, $\mathrm{Zn}^{2+}, \mathrm{Cd}^{2+}$, and $\mathrm{Hg}^{2+}$ ), and $\mathrm{Pb}^{2+}$ cation in different $\mathrm{pH}$ (Table 1) from the aqueous phase to the organic phase (Tables $2,3,4,5$, and 6). Figure 1 illustrates the formulas of the extractants used (L1-L4) in this study.

When tables and graphs are examined, it was found that crown ether groups having oxime groups have greater cation carrying ability. Crown ether cycle includes oxygen atoms which are hard atoms. So metals such as $\mathrm{Co}^{2+}, \mathrm{Ni}^{2+}, \mathrm{Cu}^{2+}$, 
TABLE 3: Extraction of metal cations with L2 (\%).

\begin{tabular}{lcccc}
\hline \multirow{2}{*}{ Metals } & \multicolumn{4}{c}{ \% Extraction } \\
& $\mathrm{pH} \cong 2,00$ & $\mathrm{pH} \cong 3,00$ & $\mathrm{pH} \cong 4,00$ & $\mathrm{pH} \cong 5,00$ \\
\hline $\mathrm{Ni}^{+2}$ & $59,84 \pm 0,62$ & $18,27 \pm 0,55$ & $7,80 \pm 0,14$ & $4,54 \pm 0,21$ \\
$\mathrm{Co}^{+2}$ & $70,84 \pm 0,96$ & $21,67 \pm 0,29$ & $10,69 \pm 0,26$ & $12,88 \pm 0,31$ \\
$\mathrm{Cu}^{+2}$ & $65,97 \pm 0,35$ & $94,61 \pm 1,44$ & $97,28 \pm 1,73$ & $97,63 \pm 1,58$ \\
$\mathrm{Zn}^{+2}$ & $68,54 \pm 0,91$ & $16,70 \pm 0,19$ & $0,1 \pm 0,09$ & $0,1 \pm 0,08$ \\
$\mathrm{Cd}^{+2}$ & $68,00 \pm 0,46$ & $22,91 \pm 0,64$ & $7,55 \pm 0,11$ & $1,50 \pm 0,10$ \\
$\mathrm{~Pb}^{+2}$ & $64,21 \pm 1,16$ & $19,30 \pm 0,39$ & $7,10 \pm 0,26$ & $3,99 \pm 0,36$ \\
$\mathrm{Hg}^{+2}$ & $66,48 \pm 1,30$ & $63,90 \pm 1,89$ & $45,21 \pm 0,94$ & $20,18 \pm 0,71$ \\
\hline
\end{tabular}

TABLE 4: Extraction of metal cations with L3 (\%).

\begin{tabular}{lcccc}
\hline \multirow{2}{*}{ Metals } & \multicolumn{4}{c}{ \% Extraction } \\
& $\mathrm{pH} \cong 2,00$ & $\mathrm{pH} \cong 3,00$ & $\mathrm{pH} \cong 4,00$ & $\mathrm{pH} \cong 5,00$ \\
\hline $\mathrm{Ni}^{+2}$ & $56,59 \pm 0,69$ & $15,38 \pm 0,30$ & $9,94 \pm 0,39$ & $4,31 \pm 0,28$ \\
$\mathrm{Co}^{+2}$ & $73,00 \pm 0,88$ & $28,73 \pm 0,49$ & $20,33 \pm 0,44$ & $5,63 \pm 0,19$ \\
$\mathrm{Cu}^{+2}$ & $78,28 \pm 1,50$ & $80,24 \pm 1,77$ & $82,09 \pm 1,82$ & $83,66 \pm 1,34$ \\
$\mathrm{Zn}^{+2}$ & $49,57 \pm 0,74$ & $25,13 \pm 0,65$ & $15,88 \pm 0,33$ & $14,48 \pm 0,27$ \\
$\mathrm{Cd}^{+2}$ & $69,39 \pm 0,84$ & $24,51 \pm 0,56$ & $10,81 \pm 0,42$ & $9,03 \pm 0,57$ \\
$\mathrm{~Pb}^{+2}$ & $50,83 \pm 0,69$ & $20,14 \pm 0,55$ & $18,97 \pm 0,68$ & $17,79 \pm 0,41$ \\
$\mathrm{Hg}^{+2}$ & $76,29 \pm 0,93$ & $65,70 \pm 0,81$ & $50,12 \pm 0,77$ & $20,23 \pm 0,59$ \\
\hline
\end{tabular}

TABLE 5: Extraction of metal cations with L4 (\%).

\begin{tabular}{lcccc}
\hline \multirow{2}{*}{ Metals } & \multicolumn{4}{c}{ \% Extraction } \\
& $\mathrm{pH} \cong 2,00$ & $\mathrm{pH} \cong 3,00$ & $\mathrm{pH} \cong 4,00$ & $\mathrm{pH} \cong 5,00$ \\
\hline $\mathrm{Ni}^{+2}$ & $59,34 \pm 0,83$ & $70,67 \pm 1,19$ & $78,19 \pm 1,38$ & $67,35 \pm 0,97$ \\
$\mathrm{Co}^{+2}$ & $40,48 \pm 0,56$ & $62,62 \pm 0,70$ & $69,83 \pm 1,03$ & $71,83 \pm 1,42$ \\
$\mathrm{Cu}^{+2}$ & $33,13 \pm 0,87$ & $72,55 \pm 1,74$ & $79,70 \pm 1,50$ & $79,16 \pm 1,64$ \\
$\mathrm{Zn}^{+2}$ & $56,83 \pm 0,26$ & $70,53 \pm 0,94$ & $73,46 \pm 1,06$ & $78,04 \pm 1,23$ \\
$\mathrm{Cd}^{+2}$ & $39,75 \pm 0,64$ & $57,99 \pm 0,69$ & $70,02 \pm 0,87$ & $57,85 \pm 0,66$ \\
$\mathrm{~Pb}^{+2}$ & $37,63 \pm 0,34$ & $56,14 \pm 0,75$ & $56,86 \pm 0,81$ & $71,32 \pm 0,24$ \\
$\mathrm{Hg}^{+2}$ & $74,00 \pm 0,28$ & $64,46 \pm 0,84$ & $35,76 \pm 0,55$ & $30,34 \pm 0,73$ \\
\hline
\end{tabular}

TABLE 6: Extraction of alkali metal cations with ligands (L1-L4) $(\%)^{\mathrm{a}}$.

\begin{tabular}{lcccc}
\hline \multirow{2}{*}{ Ligands } & \multicolumn{4}{c}{ \% Extraction } \\
& $\mathrm{Li}^{+}$ & $\mathrm{Na}^{+}$ & $\mathrm{K}^{+}$ & $\mathrm{Cs}^{+}$ \\
\hline $\mathrm{L} 1$ & $1,12 \pm 0,29$ & $1,28 \pm 0,26$ & $3,88 \pm 0,72$ & $2,18 \pm 0,32$ \\
$\mathrm{~L} 2$ & $<1,00$ & $<1,00$ & $1,37 \pm 0,17$ & $2,10 \pm 0,14$ \\
$\mathrm{~L} 3$ & $13,79 \pm 1,54$ & $60,82 \pm 2,68$ & $31,16 \pm 1,06$ & $18,76 \pm 0,82$ \\
$\mathrm{~L} 4$ & $13,68 \pm 1,80$ & $64,84 \pm 3,02$ & $23,63 \pm 2,09$ & $18,09 \pm 0,76$ \\
\hline
\end{tabular}

${ }^{\mathrm{a}} \mathrm{H}_{2} \mathrm{O} / \mathrm{CH}_{2} \mathrm{Cl}_{2}=10 / 10(\mathrm{v} / \mathrm{v})$; [ picric acid] $=2 \times 10^{-5} \mathrm{M}$, [ligand] $=1 \times 10^{-3} \mathrm{M}$, and [metal hydroxide] $=1 \times 10^{-2} \mathrm{M}, 298 \mathrm{~K}, 1 \mathrm{~h}$ contact time.

Averages and standard deviations calculated for data are obtained from five independent extraction experiments.

$\mathrm{Zn}^{2+}, \mathrm{Cd}^{2+}, \mathrm{Hg}^{2+}$, and $\mathrm{Pb}^{2+}$ which are known as soft metals do not have any affinity to extraction. However, $\mathrm{C}=\mathrm{N}$ and $\mathrm{N}-\mathrm{O}$ groups on the oxime group that they are attached to increases the extraction ability of these ligands due to the soft donor structure of the nitrogen atoms and causes big affinity to metals [18].

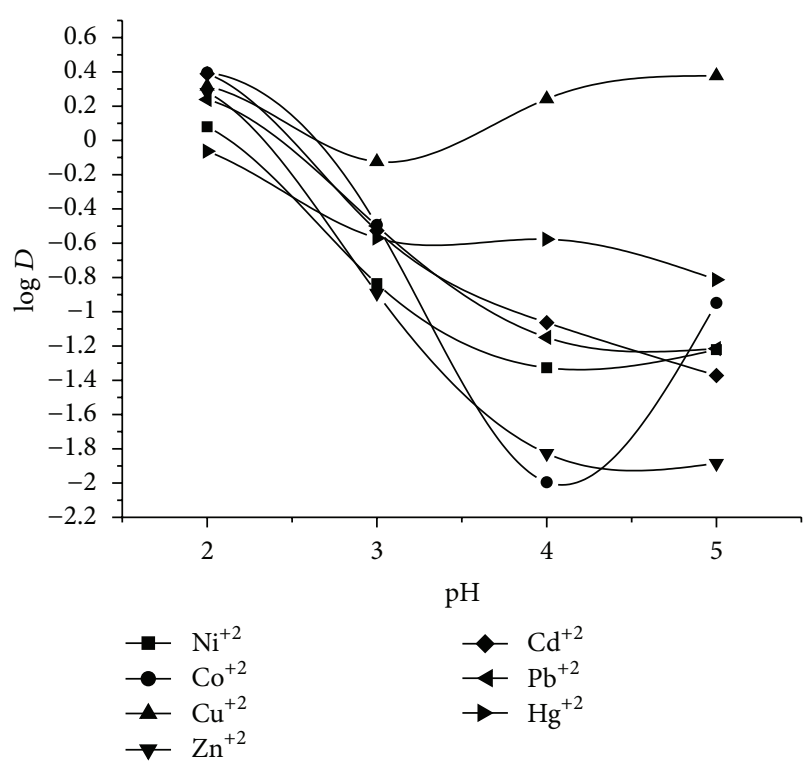

FIGURE 2: pH-log $D$ graph of L1 ligand.

$\mathbf{L} \mathbf{1}$ and $\mathbf{L} \mathbf{2}$ carry $\mathrm{pH} \cong 2$ extracted metals from aqueous phase to organic phase in large amounts. Usually, as seen in Tables 2 and 3 and Figures 2 and 3 extraction to organic phase decreases as $\mathrm{pH}$ increases. $\mathrm{In}_{\mathrm{Hg}}{ }^{2+}$ cation a slightly less decrease is observed compared to other cations. Only after $\mathrm{pH} 3$, there is an increase in $\mathrm{Cu}^{2+}$ during extraction to organic phase. This may be due to increasing tendency of metal ions to form complex over nitrogen as $\mathrm{pH}$ increases. When $\log D$ $\mathrm{pH}$ graph is examined, this tendency is more clear. In general, oxime compounds precipitation at approximately $\mathrm{pH} \cong 5$ forms complex. This event is also observed for $\mathrm{Co}^{2+}$ when $\mathrm{pH}$ increases from 4 to 5 . The $\mathrm{pH}$ range in which all the research was carried seems to be the mesh appropriate $\mathrm{pH}$ range for having no precipitation.

Generally, the effect of crown ethers and metals is connected not only with ion radius and cavity size but also with the position of donor atoms in ligand molecules and their numbers with the structural characteristics of the wholemolecule, conformational changes forming during the effect with metals and with the other mentioned factors. Among extracted metals that worked at cavity radii $\cong 1.72 \AA \mathrm{Cd}^{2+}$ ion radius were very close to each other $\cong 1.94 \AA$, but it was observed that $\mathrm{Cd}^{2+}$ was not active in extraction [31].

When extraction to organic phase in there is an increase $\mathrm{Cu}^{2+}, \mathrm{Ni}^{2+}, \mathrm{Cd}^{2+}$, and $\mathrm{Pb}^{2+}$ until $\mathrm{pH} \cong 3.00$. When $\mathrm{pH}-$ $\log D$ graph of L3 (Figure 4) and L4 (Figure 5) is examined the decrease of $\log D$ value of $\mathrm{Hg}^{2+}$ is clearly seen. For the remaining metal cations, partially increasing logarithmic curves are observed. It can be said that for this ligand (L4) in pH 2.00-5.00 range metal extraction can be done.

When $\mathrm{pH}$ increases, distribution coefficient has to increase too. But as the structure of ligands does not suit the general mechanism, logarithmic curves are observed.

The slopes of linear parts of $\mathrm{pH}-\log D$ graph are usually in fractional numbers. According to Zolotov et al. [32, 33], 


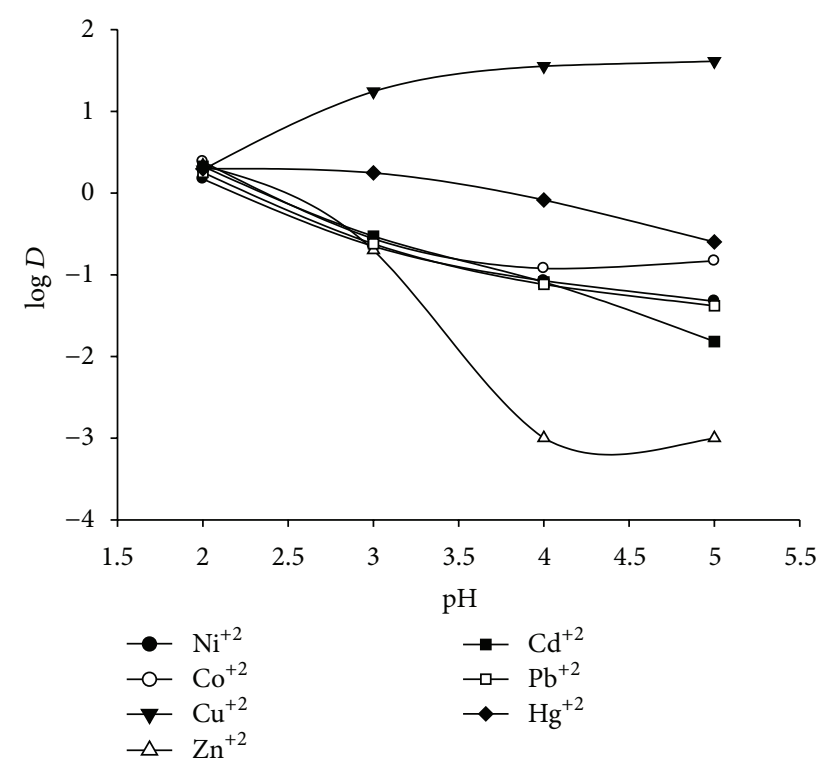

FIGURE 3: pH-log D graph of L2 ligand.

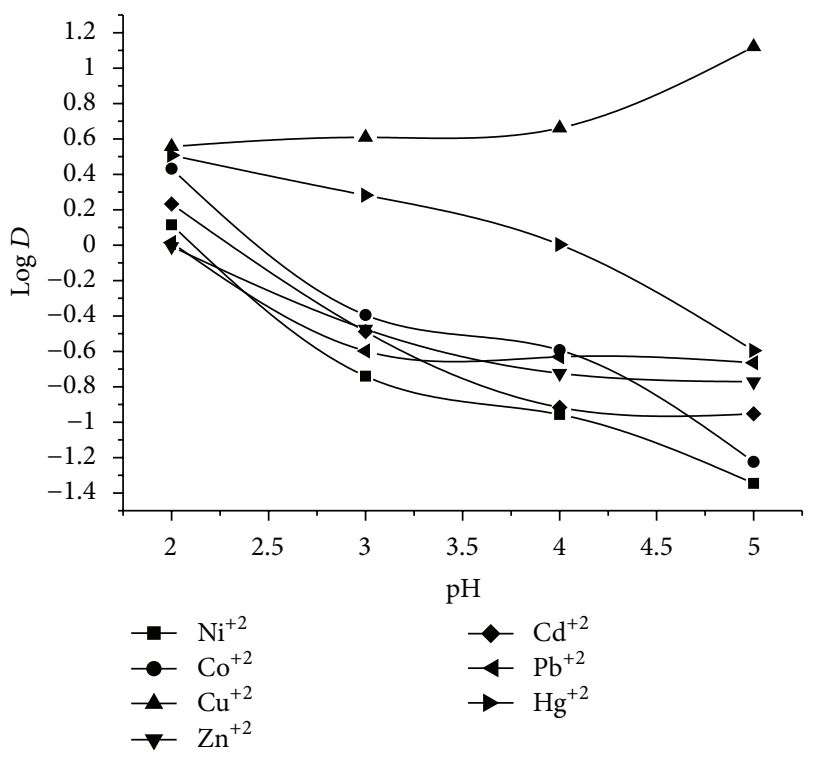

FIGURE 4: pH-log D graph of L3 ligand.

as certain parts of these graphs show protonation or deprotonations while descending parts show metal hydrolyses. However, according to some author all the experimentas were done to calculate $\mathrm{pH}$ curves resulting in different shaped curves in each trial.

It is not correct to explain the carry of extracted metals by crown ether oxime groups to cation radius. Even though $\mathrm{Hg}^{2+}$ cation radius is very close to $\mathrm{Cd}^{2+}$ radius, their extraction values are very different the same case was examined by Yordanov and Roundhill who commented on crown ether and calixarene extractions [31].

Even though complex to make inclination of oxime groups to nickel metal is big of oxime groups to nickel metal,

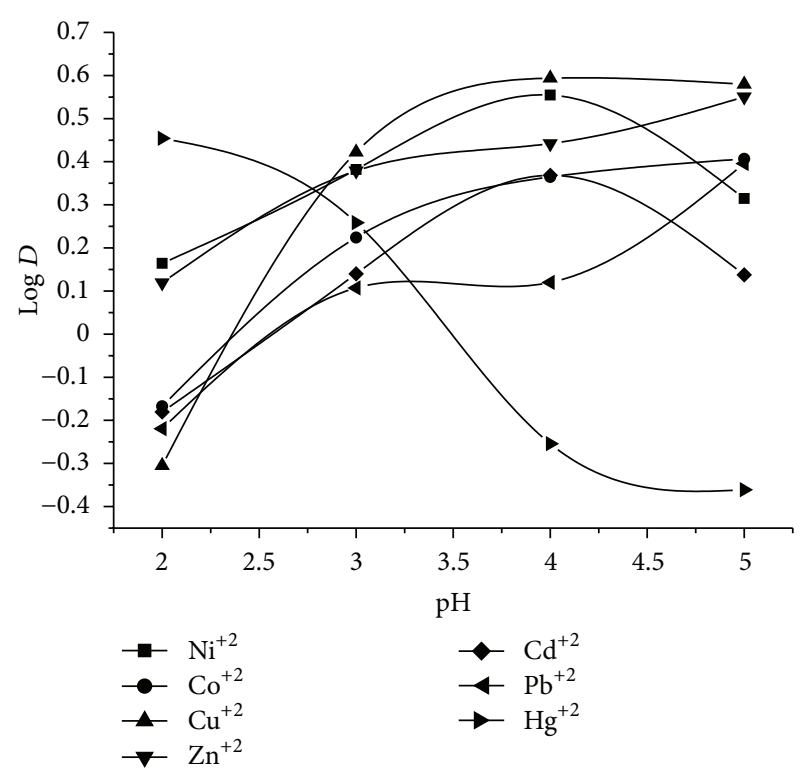

FIGURE 5: pH- $\log D$ graph of L4 ligand.

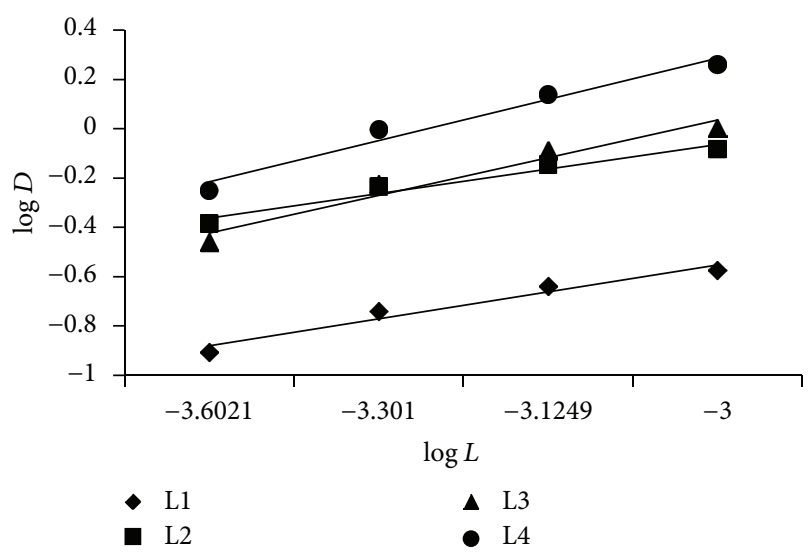

Figure 6: Plots of $\log D$ versus $\log \mathrm{L}$ for $\mathrm{Hg}^{2+}$ of ligands.

extraction percent is lower compared to copper. Dioxime compounds usually form $\mathrm{N}, \mathrm{N}$, or $\mathrm{N}, \mathrm{O}$ chelate complexes. That complex formation is related to the type of the donor atom, ligand structure, and stability of the complex, and solubility of complex is examined; when compared to extraction data of similar oximes in the literature [24-30, 34], it is seen that ligands used in our research except the commercial ones extract copper in big amounts. It is surprising that $\mathrm{Hg}^{2+}$ also can be carried when $\mathrm{Hg}^{2+}$ is extracted in large values at $\mathrm{pH} \cong$ 2 as seen in previously given extraction Tables $2-5$. It was observed that oximes can be used in liquid-liquid extraction as they include $\mathrm{N}$ group.

Metal-ligand ratio of all ligands is $1: 1$ for $\mathrm{Cu}^{2+}$. Metalligand ratio of oximes not having crown ether group is $1: 2$ for $\mathrm{Hg}^{2+}$. And metal-ligand ratio of oximes having crown ether groups for $\mathrm{Hg}^{2+}$ is $1: 1$. Inoue and friends [35] have put forward that one of the reasons of the observed unordinary stoichiometricals is the lack of harmony of metals and cycle 


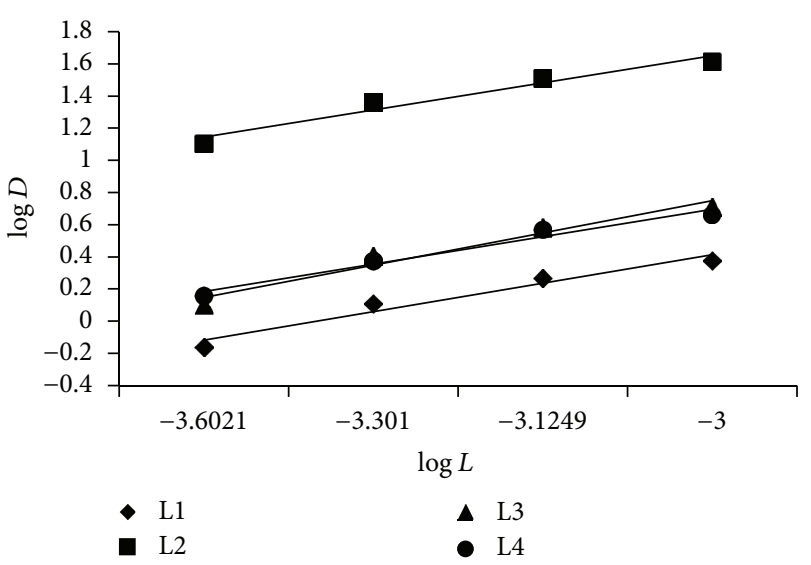

Figure 7: Plots of $\log D$ versus $\log \mathrm{L}$ for $\mathrm{Cu}^{2+}$ of ligands.

size. Normally as metal would coordinate with nitrogen due to oxime terminal metal: ligand ratio should be $2: 1$. Here, complexes in the extraction and solid phases resemble each other especially for their characteristic structures. The reason is that, in both phases, there is not strong solvation.

The obtained extraction results of $\mathbf{L 1}-\mathbf{L} \mathbf{4}$ with the series of metal cations: alkali metals $\left(\mathrm{Li}^{+}, \mathrm{Na}^{+}, \mathrm{K}^{+}\right.$, and $\left.\mathrm{Cs}^{+}\right)$, transition metals $\left(\mathrm{Co}^{2+}, \mathrm{Ni}^{2+}, \mathrm{Cu}^{2+}, \mathrm{Zn}^{2+}, \mathrm{Cd}^{2+}\right.$, and $\left.\mathrm{Hg}^{2+}\right)$, and $\mathrm{Pb}^{2+}$ are given in Tables $2-6$. These results indicate that the compoundscan be used for extraction especially of $\mathrm{Cu}^{2+}$ metal cations, which is containing this metal cation. The extractions of selected metal cations with $\mathbf{L} \mathbf{2}$ are much before than those of other compounds.

The solvent extracted $\mathrm{Cu}^{2+}$ and $\mathrm{Hg}^{2+}$ metal cations into $\mathrm{CH}_{2} \mathrm{Cl}_{2}$ at different concentrations of $\mathbf{L 1}-\mathbf{L} 4$ are shown in Figures 6 and 7. The obtained $\log D$ versus $\log L$ plot displayed in Figures 6 and 7 is shown as 1:1 in ratio of metal-ligand for $\mathrm{Cu}^{2+}$ with $\mathbf{L 1}-\mathbf{L} 4$ and for $\mathrm{Hg}^{2+}$ with $\mathbf{L 3}, \mathbf{L 4}$ and $1: 2$ in ratio of metal : ligand for $\mathrm{Hg}^{2+}$ with $\mathbf{L 1}, \mathbf{L} 2$.

The proposed equation is described as follows:

$$
\log D=\log K_{\mathrm{ex}}+\log \left[\mathrm{Pic}^{-}\right]^{n}+x \log [\mathrm{L}] .
$$

The slopes of curves in the extraction of $\mathrm{Cu}^{2+}$ and $\mathrm{Hg}^{2+}$ with L1-L4 are describes later. It can therefore suggest that the ratio of metal-ligand is $1: 1$ or $1: 2$ due to probably zwitter ion character of ligands containing $\mathrm{O}$ and $\mathrm{N}$ atoms:

$$
\begin{aligned}
& n=+2 ; \mathrm{M}=\mathrm{Cu}, x=0.896(\mathrm{~L} 1), 0.850(\mathrm{~L} 2), 1.012(\mathrm{~L} 3) \\
& 0.852(\mathrm{~L} 4), \text { respectively, } \\
& n=+2 ; \mathrm{M}=\mathrm{Hg} ; x=0.554(\mathrm{~L} 1), 0.502(\mathrm{~L} 2), 0.773(\mathrm{~L} 3) \\
& 0.838(\mathrm{~L} 4), \text { respectively. }
\end{aligned}
$$

The logarithmic extraction constant $\log K_{\mathrm{ex}}\left(K_{\mathrm{ex}}\right.$ in $\mathrm{mol} / \mathrm{L}$ ) corresponding to (6) is calculated:

$\log K_{\mathrm{ex}}=12.27,13.37,12.94,12.39$ for $\mathrm{Cu}^{2+}$ with L1-L4, respectively,

$\log K_{\mathrm{ex}}=10.29,10.62,11.53,11.97$ for $\mathrm{Hg}^{2+}$ with L1-L4, respectively.

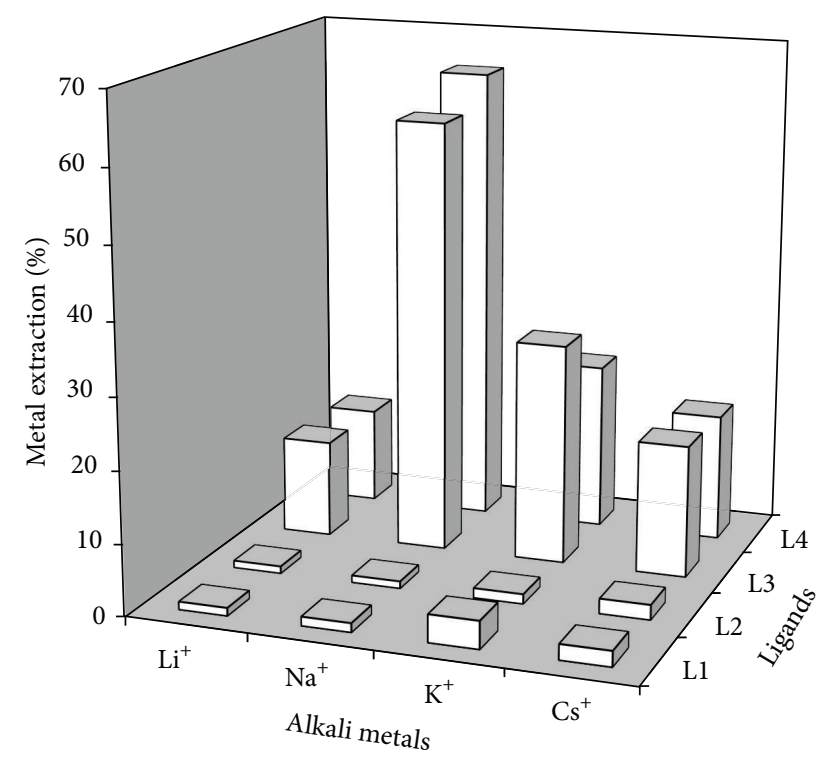

FIGURE 8: Extraction of alkali metal cations with ligands.

Since IA group cations are at hard characteristic, according to hard-soft acid-base rule, hard metals react with hard donor group and soft metals react with soft donor groups. So, extraction characteristics against alkali metals of oximes having and not having crown ethers were examined.

Oxime derivatives of crown ether (L3-L4) are very effective in transferring the alkali metal cations. Crown ether groups having ligands carry all alkali metals from aqueous phase to organic phase, but especially $\mathrm{Na}^{+}$cation is carried clearly. As seen in Table 6 and Figure 8, this is due to the appropriateness of the ion diameter of $\mathrm{Na}^{+}$ion and cavity of crown ether cycle. Cavity diameter of crown ether cycle is $1.72-1.54 \AA$, and ion radius of sodium ion is $\mathrm{R}: 1.90 \AA$.

The previously mentioned phenomena can be explained by the (hard-soft) acid-base principle as follows: $\mathrm{C}=\mathrm{N}-\mathrm{OH}$ is a soft base and hence has stronger affinity towards soft basic metal cations than hard metal cations. The strong participation of the $\mathrm{N}-\mathrm{OH}$ group in complex formation was further confirmed by the results shown for extraction experiments with ligands.

The results of solvent extraction of alkali metal picrates from aqueous phase to dichloromethane phase with oxime derivatives of crown ether are summarized in Table 6. It is known that 15 membered all-oxygen crown ethers have high selectivity for $\mathrm{Na}^{+}$ion. $\mathbf{L} 3$ and $\mathbf{L} 4$ shows approximately similar extractability against the other alkali metal cations $\left(\mathrm{Li}^{+}, \mathrm{K}^{+}\right.$, and $\left.\mathrm{Cs}^{+}\right)$and shows no selectivity for these cations when $\mathrm{pH}$ is 7.0. A selectivity becomes apparent as in the order $\mathrm{Na}^{+}>\mathrm{K}^{+}>\mathrm{Cs}^{+}>\mathrm{Li}^{+}$.

Previous investigations on solvent extraction of alkali metal cations from aqueous phase into organic solvents with all-oxygen crown ethers such as 12-crown-4, 15-crown-5 and 18-crown-6 indicate that the following orders are common trends $\mathrm{Li}^{+} \gg \mathrm{Na}^{+}>\mathrm{K}^{+}>\mathrm{Rb}^{+}>\mathrm{Cs}^{+}>\mathrm{Na}^{+} \gg \mathrm{K}^{+}>$ $\mathrm{Rb}^{+}>\mathrm{Cs}^{+}>\mathrm{Li}^{+}$, and $\mathrm{K}^{+} \gg \mathrm{Rb}^{+}>\mathrm{Cs}^{+}>\mathrm{Na}^{+}>\mathrm{Li}^{+}$, respectively. These orders are explained in terms of the 
relationship between the crystal radius of metal ions and the size of crown ethers $[36,37]$. In our alkali metal extraction experiments for oxime compounds having the same crown ether group, $\mathrm{Na}^{+}>\mathrm{K}^{+}>\mathrm{Cs}^{+}>\mathrm{Li}^{+}$activity order was observed. And this is in favour of the literature.

\section{Acknowledgment}

This work was supported by the Scientific Research Council of Selcuk University, Turkey.

\section{References}

[1] T. C. Chu and C. C. Lin, "The solvent extraction of radium using sym-Di[4(5)-tert-butylbenzo]-16-crown-5-oxyacetic acid," Applied Radiation and Isotopes, vol. 55, no. 5, pp. 609-616, 2001.

[2] M. K. Beklemishev, S. G. Dmitrienko, and N. V. Isakora, "Solvent extraction of metal with macrocyclic reagents and its analytical applications," in Macrocyclic Compounds in Analytical Chemistry, pp. 67-87, John Wiley \& Sons, New York, NY, USA, 1997.

[3] Y. Inoue, Y. Liu, L. H. Tong, A. Tai, and T. Hakushi, "Molecular design of crown ethers. 6. Substitution effect in 16-crown-5," Journal of the Chemical Society, Chemical Communications, pp. 1556-1557, 1989.

[4] C. J. Pedersen, "Cyclic polyethers and their complexes with metal salts," Journal of the American Chemical Society, vol. 8, no. 26, pp. 7017-7036, 1967.

[5] S. Shinkai, M. Ishihara, K. Ueda, and O. Manabe, "Photoresponsive crown ethers. Part 14. Photoregulated crown-metal complexation by competitive intramolecular tail(ammonium)biting," Journal of the Chemical Society, Perkin Transactions 2, no. 4, pp. 511-518, 1985.

[6] Y. Gok, "The synthesis and characterization of novel tetraoxime and its mono- and polynuclear complexes containing 12membered diaza-dithia macrocycles," Polyhedron, vol. 15, no. 8, pp. 1355-1361, 1996.

[7] Y. Gok, "The synthesis and characterization of new substituted diaminoglyoxime and its cobalt(III) complexes containing 15membered dioxa-trithia macrocyclic moieties," Polyhedron, vol. 15, no. 22, pp. 3933-3940, 1996.

[8] Y. Gok, S. Karabocek, and H. Kantekin, "Axial-ligation and macrocyclization of novel (E, E)-dioximes of nickel(II) palladium(II), platinum(II) and cobalt(III)," Transition Metal Chemistry, vol. 20, no. 3, pp. 234-238, 1995.

[9] E. Karapinar, N. Karapinar, and E. Özcan, 'Synthesis of N'-(4'benzo[15-crown-5])-phenylaminoglyoxime and its complexes with copper(II), nickel(II), and cobalt(II)," Synthesis and Reactivity in Inorganic and Metal-Organic Chemistry, vol. 33, no. 8, pp. 1319-1328, 2003.

[10] E. Karapinar and E. Ozcan, 'Synthesis of $N$ '-[4'-benzo(15crown-5)]-4-tolylaminoglyoxime and $N^{\prime}$-[4'-benzo(15-crown5)]-4-chlorophenylaminoglyoxime and their complexes with copper (II), nickel (II) and cobalt (II)," Journal of Inclusion Phenomena, vol. 47, no. 1-2, pp. 59-63, 2003.

[11] E. Karapinar, N. Karapinar, and E. Ozcan, "Synthesis of N(4'benzo[15-crown-5])biphenylaminoglyoxime and its complexes with some transition metals," Koordinatsionnaya Khimiya, vol. 30, no. 7, pp. 491-495, 2004.

[12] H. I. Ucan and R. Mirzaoglu, "Synthesis and complexes formation of six new unsymmetrical vic-dioximes," Synthesis and
Reactivity in Inorganic and Metal-Organic Chemistry, vol. 20, no. 4, pp. 437-449, 1990.

[13] J. V. Burakevich, A. M. Lore, and G. P. Volpp, "Phenylglyoxime. Separation, characterization, and structure of three isomers," Journal of Organic Chemistry, vol. 36, no. 1, pp. 1-4, 1971.

[14] H. C. Sevindir and R. Mirzaoglu, "Synthesis and complexformation of 4 new unsymmetrical vic-dioximes," Synthesis and Reactivity in Inorganic and Metal-Organic Chemistry, vol. 22, no. 6, pp. 851-861, 1992.

[15] A. İ. Pekacar and E. Ozcan, "Synthesis and complex formation of substituted amino-p-chlorophenylglyoximes of unsymmetrical vic-dioximes," Macromolecular Reports, vol. 32, no. 8, pp. 11611169, 1995.

[16] A. İ. Pekacar and E. Ozcan, "Synthesis and complex formation of new unsymmetrical vic-dioximes," Synthesis and Reactivity in Inorganic and Metal-Organic Chemistry, vol. 25, no. 6, pp. 859868, 1995.

[17] I. Karataş and H. I. Uçan, "The synthesis of biphenylglyoxime and bis(biphenylglyoxime) and their complexes with $\mathrm{Cu}(\mathrm{II})$, $\mathrm{Ni}(\mathrm{II})$ and $\mathrm{Co}(\mathrm{II})$," Synthesis and Reactivity in Inorganic and Metal-Organic Chemistry, vol. 28, no. 3, pp. 383-391, 1998.

[18] R. Gup, H. K. Alpoğuz, and A. D. Bedük, "Synthesis and extraction properties of 1, 2-bis(amidoxime) derivatives," Collection of Czechoslovak Chemical Communication, vol. 67, pp. 209-218, 2002.

[19] H. Deligoz and M. Yilmaz, "Liquid-liquid extraction of transition metal cation by calixarenes-based cyclic ligands," Solvent Extraction and Ion Exchange, vol. 13, pp. 19-26, 1995.

[20] B. Ziyadanoğullari, G. Topal, S. Erdoǧan, C. Hamamci, and H. Hoşgoren, "Effect of structural modifications of diaza-18crown- 6 on the extractability and selectivity of univalent metal picrates," Talanta, vol. 53, no. 5, pp. 1083-1087, 2001.

[21] C. Hamamci, H. Hoşgören, and S. Erdogan, "The solvent extraction of alkali metal picrates with 4,13- $N, N^{\prime}$-dibenzyl-4,13diaza-18-crown-6," Talanta, vol. 47, no. 1, pp. 229-236, 1998.

[22] A. Grün, V. Csokai, G. Parlagh, and I. Bitter, "Synthesis and alkali cation extraction ability of 1,3-alt-thiacalix[4]bis(crown) ethers," Tetrahedron Letters, vol. 43, no. 23, pp. 4153-4156, 2002.

[23] Y. Takeda, C. Takagi, S. Nakai, K. Endo, and S. Katsuta, "Extraction of sodium and potassium picrates with 16-crown5 into various diluents. Elucidation of fundamental equilibria determining the extraction selectivity for $\mathrm{Na}^{+}$over $\mathrm{K}_{+}$," Talanta, vol. 48, no. 3, pp. 559-569, 1999.

[24] L. R. M. Paping, T. P. M. Beelen, C. P. J. Rummens, and R. Prins, "Extraction of $\mathrm{Cu}(\mathrm{II})$ and $\mathrm{Ni}(\mathrm{II})$ by camphorquinone dioxime," Polyhedron, vol. 1, no. 6, pp. 503-510, 1982.

[25] L. R. M. Paping, T. P. M. Beelen, M. Mols, and R. Prins, "Extraction of copper(II) and nickel(II) by cyclic trioximes and cyclic furazan oximes," Polyhedron, vol. 3, no. 4, pp. 479-484, 1984.

[26] L. R. M. Paping, T. P. M. Beelen, M. Mols, J. H. M. C. van Wolput, and R. Prins, "Extraction of copper(II) and nickel(II) by nopinoquinone dioxime," Polyhedron, vol. 3, no. 7, pp. 821831, 1984.

[27] L. Calligaro, A. Mantovani, U. Belluco, and M. Acampora, "Solvent extraction of copper(II), nickel(II), cobalt(II), zinc(II), and iron(Ill) by high molecular weight hydroxyoximes," Polyhedron, vol. 2, no. 11, pp. 1189-1193, 1983.

[28] K. S. Rao, N. B. Devi, and B. R. Reddy, "Solvent extraction of copper from sulphate medium using MOC 45 as extractant," Hydrometallurgy, vol. 57, no. 3, pp. 269-275, 2000. 
[29] S. Kuse, S. Motomizu, and K. Tôei, "o-Diketonedioxime compounds as analytical reagents for the spectrophotometric determination of nickel," Analytica Chimica Acta, vol. 70, no. 1, pp. 65-76, 1974.

[30] J.S. Preston, "Solvent extraction of nickel and cobalt by mixtures of carboxylic acids and non-chelating oximes," Hydrometallurgy, vol. 11, no. 1, pp. 105-124, 1983.

[31] A. T. Yordanov and D. M. Roundhill, "Chemically modified calix[4]arenes as selective complexants for heavy metal ions: comparison with crowns and thiacrowns," New Journal of Chemistry, vol. 20, no. 4, pp. 447-451, 1996.

[32] Y. A. Zolotov, N. M. Kuz'min, O. M. Petrukhin, and B. A. Spivakov, "Liquid-liquid extraction in inorganic analysis: current status and prospects," Analytica Chimica Acta, vol. 180, pp. 137-161, 1986.

[33] Y. A. Zolotov, Macrocyclic Compounds in Analytical Chemistry, edited by J. D. Winefordner, John Wiley \& Sons, Weinheim, Germany, 1997.

[34] A. M. Sastre and F. J. Alguacil, "Co-extraction and selective stripping of copper (II) and molybdenum (VI) using LIX 622," Chemical Engineering Journal, vol. 81, no. 1-3, pp. 109-112, 2001.

[35] Y. Inoue, Y. Liu, F. Amano, M. Ouchi, A. Tai, and T. Hakushi, "Uncommon complex stoicheiometry in solvent extraction: solution-phase dicationic complex formation of crown ethers," Journal of the Chemical Society, Dalton Transactions, no. 11, pp. 2735-2738, 1988.

[36] K. Kimura, T. Maeda, and T. Shono, "Extraction of alkali metal picrates with poly- and bis(crown ether)s," Talanta, vol. 26, no. 10, pp. 945-949, 1979.

[37] S. Kitazawa, K. Kimura, H. Yano, and T. Shono, "Lipophilic crown-4 derivatives as lithium ionophores," Journal of the American Chemical Society, vol. 106, no. 23, pp. 6978-6983, 1984. 

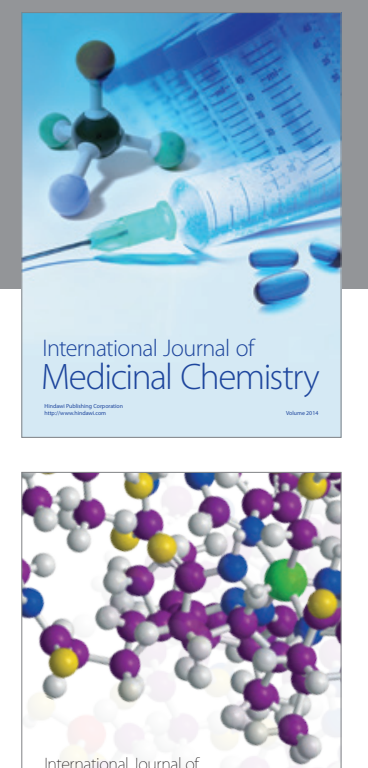

\section{Carbohydrate} Chemistry

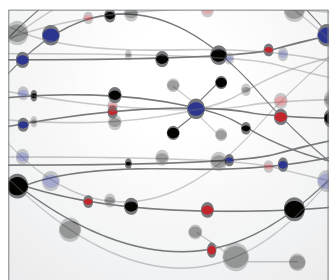

The Scientific World Journal
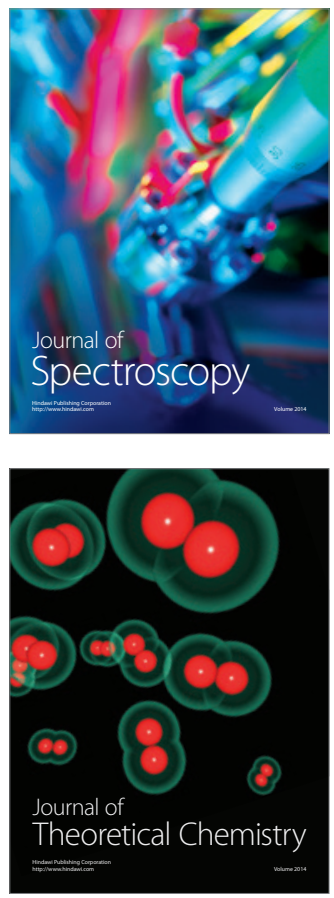
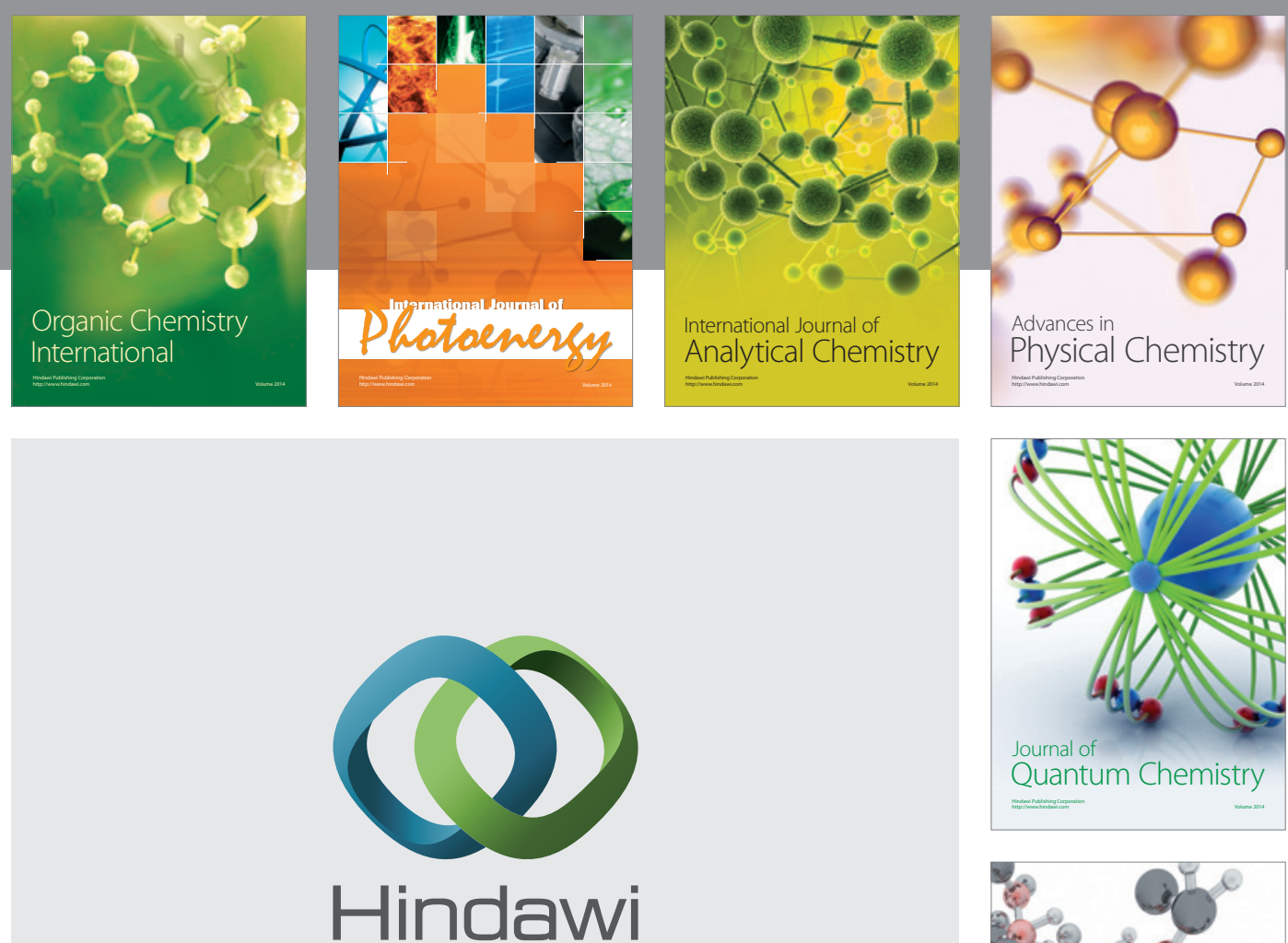

Submit your manuscripts at

http://www.hindawi.com

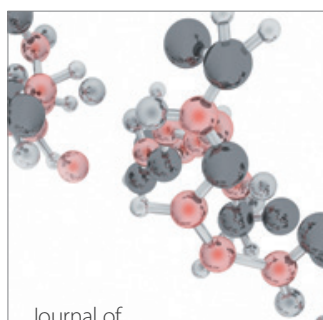

Analytical Methods

in Chemistry

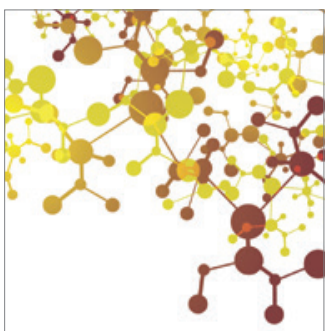

Journal of

Applied Chemistry

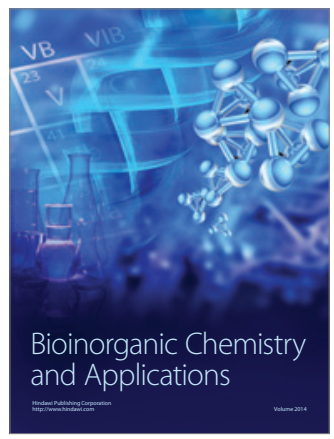

Inorganic Chemistry
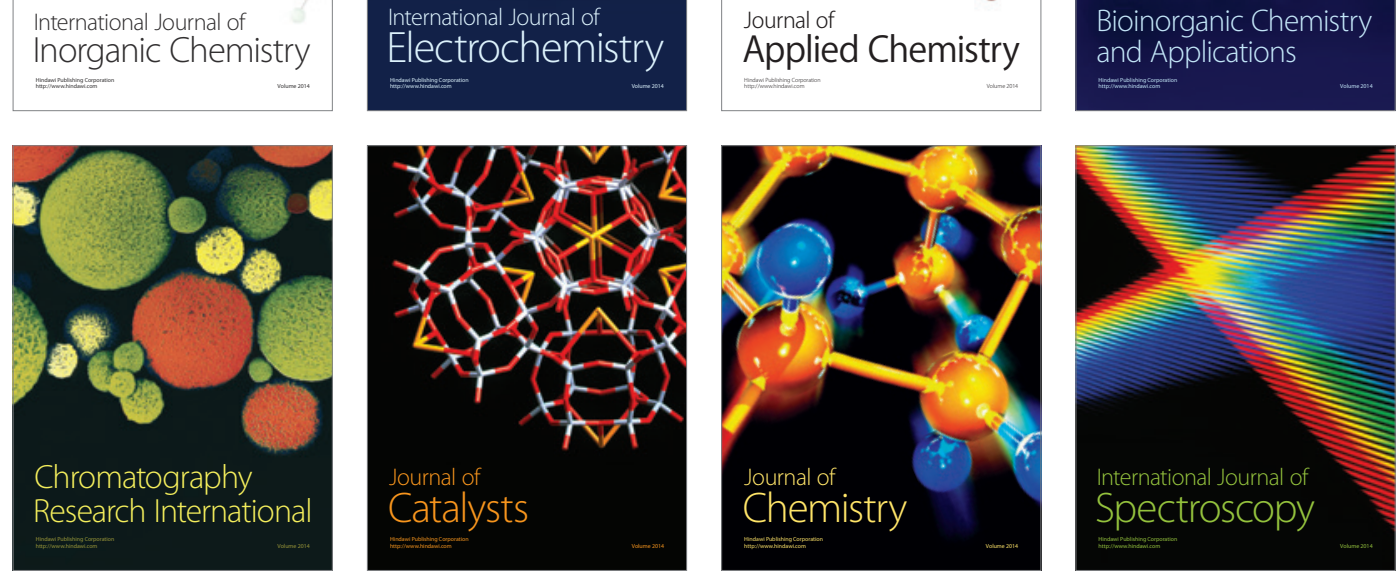